\title{
6
}

\section{EXTRACTION AND THE BUILT ENVIRONMENT}

\section{Violence and Other Social Consequences of Construction}

\author{
Victoria Kiechel
}

\section{Introduction}

A domed indoor forest enclosing some 3,000 trees, Terminal 3 at Singapore's Changi Airport houses the world's largest indoor waterfall, the 40-meter-tall Rain Vortex. Finished in 2019 as the capstone of the nearly \$1 billion Jewel development, the technological audacity, innovative construction techniques, and biophilic beauty within this constructed biodome makes the airport itself a destination, providing, according to Changi's Chief Executive Officer, "a unique proposition of world-class shopping and dining, seamlessly integrated with lush greenery" to fulfill "the needs of increasingly discerning travelers for a meaningful and experiential journey" (Morris, 2019). The online sustainability journal Treehugger dubbed the Rain Vortex a "show-stopping centerpiece" featuring rainwater harvesting in an “exceptionally clean 'n' green Singapore” (Hickman, 2019). The Dirt, the online journal of the American Society of Landscape Architects, praised the airport terminal's restorative powers, citing how "immersion in nature can reduce stress, restore cognitive ability, and improve mood" (Green, 2019). Engineering News-Record quotes members of the design team describing it as a "new typology," "powerful," and "amazing" (Post, 2019) as a technical tour-de-force of construction.

But a consideration of the broader social and environmental context of Terminal 3 reveals a global reality: many of our most "clean," "green," and spectacular buildings and infrastructure owe their existence to extractive violence, the harmful effects of which could be remote or only slowly revealed.

As the celebratory products of human imagination, buildings and infrastructure embody social status, wealth, and power. They confer prestige upon their sponsors and their sites while, as in the case of Changi's Terminal 3, they supercharge futuristic civic identities, a move deemed essential for competitive urban advancement. Less visible is the trail of extractive impacts and social and ecological violence 
contained within some of the most renowned buildings and infrastructure of recent generations. Beautiful projects, even ones that are certified or considered to be "green," might come at a tremendous human and environmental cost. Singapore, like other globally competitive cities, relies on labor extracted from nations in the Global South (Hirschmann, 2020), with workers living in conditions tantamount to indentured servitude; builds on reclaimed land built on sand extracted from Indonesia, Malaysia, and Cambodia, nations that have begun to refuse sand export as they see the ecological and human consequences of this depletion (Subramanian, 2017); and depends on extraction of material components (aggregate for concrete, silica for glass, and more) used in construction - a process causing human health and environmental harm in the geographies where these components are sourced, remote from building sites. Worldwide, spectacular and iconic objects-high towers, sports stadia, bridge and road infrastructure, recreational spaces, landmark office buildings and residential developments - that through their technological brilliance, superior utility, and/or the beauty of their sinuous material form excite and attract us, could indeed be among the more lastingly violent of human achievements. Consider that the construction of the U.S. highway system in the twentieth century is estimated to have displaced 500,000 U.S. urban households, most of which comprised low-income people of color (Schmitt, 2016; Halsey, 2016). Destruction of urban neighborhoods and their social fabric has been a feature of sports venue development for recent Olympic Games (Donahue, 2020). Even after global attention to the issue (Amnesty International, 2016), estimates of migrant worker deaths related to the construction of the Qatar stadia for the 2022 World Cup remain in the thousands (DAMfirm, n.d.).

In a seeming paradox, construction involves destruction-not only of raw material stocks, but often of local economies excluded from benefit, of the sociospatial fabric of neighborhoods, and of construction workers themselves. The built environment, whether beneficial or oppressive in its social and ecological effects, owes its very existence to extractive actions. If in choosing to build we cannot eliminate extraction, we can deconstruct the violence of extractive impacts by making their harm, and their influence over time, publicly visible, and by giving the power of decision-making to the communities most vulnerable to these impacts. In doing so we must consider the status of the architectural object and the role and power of domestic and international boundary-crossers, both globalized and globalizing, in the extractivist world of construction-real estate investors and their financial capital; architects and designers and their knowledge capital; construction firms and their human capital (construction workers); the materials and methods of design and construction - to forge a path towards the goal of a less extractive, less discordant, and more just and equitable built environment.

This essay identifies three forms of extractivism inherent in the design and construction of the contemporary built environment: (1) global real estate investment, which invests capital in the built environment for the future extraction of profit for investors; (2) the trend towards "hyperbuilding" as cities and regions compete for global recognition and investment-a trend in which global design and material 
supply chains feed a delirium of resource extraction and the mismatch between global expectations and local realities, with the potential for increased social conflict and vulnerability to environmental degradation and climate change; (3) the consequent displacement of humans and other species, whether due to necessity or perceived opportunity, experienced as self-extraction and self-imposed labor migration.

This chapter considers why current green building rating schemes do not include these forms of extraction as a focus, and in doing so it addresses the question of how to reformulate the frame and assessment methods of built environment projects better to reveal extractivism. Here, a redefinition of the status of the constructed object is in order, to transition our conception of it from solely a resource-consuming material thing towards an expanded alternative: that built environment projects are, and should be designed and regulated as, a connective web of social and ecological relationships that include literal and figurative territory well beyond their specific sites and material embodiments. The conclusion puts forward suggested preconditions for ground-up new construction so conceived, including the need for an outcomes-orientated process with planning and assessment methods to bring together speculators, their designers, and their affected communities in order to localize extractive effects, project their place-based influence over time, and thus deter both the slow and sudden violence arising from the consequences of development.

\section{Hyper-Extraction and Global Real Estate Investment}

While many factors contribute to making this era a hyper-extractive age in terms of the built environment, the driving impetus is the nature, origin, and intensification of the global flows of capital seeking investment in real estate and infrastructure. According to a 2019 OECD report, "investment needs" drive the construction sector, with 90 percent of global construction used for investment purposes (OECD, 2019, p. 94). Indeed, as a percentage of composition of 2017 investment expenditure by commodity, in most global geographies construction outweighed agriculture, equipment, and services - and, often, outweighed these three combined (OECD, 2019, p. 114). The commercial U.S. real estate services company Jones Lang Lasalle reported that in 2019 global commercial real estate investment in facilities such as offices, retail, industrial structures, multifamily housing, and hotels reached an all-time high of $\$ 800$ billion (Jones Lang Lasalle, 2020). Global investment in infrastructure projects is estimated at many times more, with one database tracking a mere selection of projects representing nearly $\$ 15$ trillion (Global Infrastructure Outlook 2019-2023, 2019).

So how might we define what the OECD terms the "investment needs" that drive the construction sector? These are a primary consideration in "accumulation planning" on the part of investors who seek diversified investment portfolios in order to reduce investment risk and create reliable returns. Investors seek the architectural or infrastructural object as a way to invest their capital as an alternative to global markets. The problem hinges less on the practice, per se, of investment; rather, problems arise from investor motivation and priorities, physical distance, 
limited awareness of impacts, and lack of accountability. In our financially globalized world, holders of fortunes, whether individuals, families, businesses, non-profits, sovereign wealth funds, pension funds, or states and/or corrupt states, are capable of speculative investment from great distances, detached from location and thus from the direct social effects of development impacts. There are many who aim to do social and ecological good through the medium of environmental, social, and governance (ESG) investing. Indeed, there exists the potential for good through investment in projects intended to counter extractive traditions such as racial segregation and urban ecological fragmentation and exclusion. Yet the guidelines for ESG investment are vague enough to be open to many concerns; examples include carbon-intense, violence-inducing, or socially destructive and exclusionary projects in energy and transportation infrastructure, as there is no common protocol for assessing the impacts of these projects. ${ }^{1}$ Even "green" renewable energy projects, both wind and solar, face criticism for their potential extractive impacts in their capacity for destroying habitats and reducing biodiversity. And as a leading ESG investment firm representative points out, "infrastructure debt is mostly private" (Fiastre, 2019), without publicly available information or required reporting of any kind.

Absent public input, information, and required reporting, the goal of global infrastructure and built environment investment prioritizes investor benefits in the form of return on investment: the extraction of capital rather than the construction of community. The demands for near-term return on investment could leave out considerations of longer-term economic health inherent in the production of social or ecological "capital" for enhanced future well-being and conflict reduction. Returns extracted from built environment investments rival or exceed those of the stock market, averaging nearly ten percent per year for the commercial real estate sector (Maverick, 2020) and more than ten percent per year for infrastructure (PricewaterhouseCoopers, 2017, p. 6). Consequently, global investment for the extraction of profit is widespread practice. For example, in a five-mile radius from the Washington, DC home of this author, there is a housing and retail development funded largely by the government of Qatar (CityCenter: Fisher, 2013), a waterfront mixed-use development constructed with significant foreign investment from Chinese investors (the Wharf: Clabaugh, 2015), and a toll-road between the suburbs and the city managed, for profit, by an Australian infrastructure group (Dulles Greenway: Atlas Arteria, 2020).

\section{The Violence and Delirium of Extraction}

One of the factors driving contemporary hyper-extractivism is the dynamic of global cities competing with one another for business, investment, and prestige, as they seek to evince the scale, spectacle, and technological innovation of their built environments, with grandiose new projects often designed by the same global design firms. Enter the concept of hyperbuilding, a term linked to the way governments, corporations, and investors can demonstrate the magnitude of their political, economic, and social power through built form. The renowned global architectural 
practitioner Rem Koolhaus ${ }^{2}$ promulgated the term beginning in at least 1996, but others quickly broadened its application. Aihwa Ong writes about it with respect to the emergence of Asian cities:

Hyperbuilding as a physical landmark stages sovereign power in the great city, or in cities aspiring, through these edifices, to greatness. The interactions between exception, spectacle, and speculation create conditions for hyperbuilding as both the practice and the product of world-aspiring urban innovations.

(Ong, 2011, p. 207)

The concept of "hyperbuilding" is the manifestation of hyper-extraction, where hyper-extraction is expressed either directly or indirectly: directly, as in "look at the sheer scale of this development and the amount of extracted materials it uses!" and indirectly, as in, "I have surplus wealth from my extractive economy, and it must be invested." Hyperbuilding, as embodied capital, results in building and infrastructure grand in scale, whether in height, in gross square footage and land area covered, in design or technological audacity, or in all of these together. Building thus audaciously requires considerable extraction in human, ecological, and material terms. Among the increasingly profligate, even violent, forms of hyper-extraction are the following: (1) the human extraction involved in labor migration, with worker conditions tantamount to enslavement; (2) the human extraction arising from the slow violence of community displacement; (3) the extraction of urban spatial territory for unproductive or unneeded use, leading to further displacement; (4) the project-specific extraction of ground, displacement of soil, and disruption of soil ecology; and (5) supply chain corruption for extraction of components of the material most essential to hyperbuilding: concrete.

\section{The Pull and Push of Human Extraction}

Demand for construction labor, particularly less-skilled labor, represents economic opportunity for individual workers and their families and for nations whose economies depend on remittances, which in 2018 totaled $\$ 689$ billion worldwide with $\$ 529$ billion going to developing countries (KNOMAD, 2020). The coalition Who Builds Your Architecture? (WBYA?) documented, for a 2016-17 exhibition at the Art Institute of Chicago (Who Builds Your Architecture?, n.d.), the trail of the global architectural and construction labor force for projects in four cities, Doha, Istanbul, New York, and Chicago:

Whether majestic skyscrapers, eye-catching museums, or sprawling residential complexes, buildings emerge from intricate, lengthy processes of design and construction that involve a host of different actors, from architects and engineers to clients and banks to contractors and construction workers. These relationships operate within a global network of knowledge transfer, 
manufacturing, and labor-people and materials moving around the world, often in uneven and unequal ways.

(Who Builds Your Architecture?, n.d.)

The WBYA? coalition's 2017 Critical Field Guide (Who Builds Your Architecture?, 2017 ) is in part a mapping of extractive flows, and in part a call to action to architects, beginning with a pledge for fair labor in countries where "the task of construction is designated to migrant workers who are indentured, exploited, and all but stripped of their rights" (2017, p. 9). The Guide describes the labor recruitment and migrant transport process in detail and visually maps the geographies of origin of the 685,000 migrant construction workers in Qatar, the 45,000,000 internal migrant construction workers in China, and the 500,000 migrant construction workers in the United Arab Emirates (UAE) (2017, p. 19). Even with reforms, labor abuse of construction workers in the UAE under the kafala systemincluding withholding of paychecks, inadequate living conditions, and long working shifts of twelve hours or more-is well-documented (Jacobs, 2018). U.S. construction also relies on authorized and unauthorized immigrant labor, a workforce willing to take on low-paying and often more dangerous jobs while receiving disparate treatment and lower compensation than their U.S.-born peers with annual salaries in metro areas equaling 60 percent of U.S.-born construction workers (Martin, 2016). The Brookings Institution cites that in 2010 U.S. immigrants represented about 22 percent of construction employment, making up over 60 percent of the workforce in the low-skill occupation of reinforcing iron and rebar workers and 30 percent of the carpenter, pipelayer and plumber, and mason and marble-setter workforce (Brookings Partnership for a New American Economy, n.d.). A Pew Research Center 2018 study determined that unauthorized immigrants comprise fifteen percent of the U.S. construction workforce (Passel and Cohn, 2018). The impacts of migrant extraction range from the individual and familial scale-assumption of debt to labor brokers and moneylenders, possible erosion of wages essential to familial support, ill-treatment and isolation, no recourse for injuries, absence of skills-based training - to the societal scale, with impacts on household gender roles, increased national food insecurity in the loss of agricultural labor, and the use of familial remittances to fund uneven development in peri-urban communities (Who Builds Your Architecture?, 2017, p. 17). ${ }^{3}$

In parallel with its documentation of construction labor, the WBYA? Guide visually represents selective flows of design work and capital earned, citing $\$ 1,700,000,000$ as 2013 gross billings for international projects for U.S.-based architecture firms. It also describes the distance within the process of transference of architectural knowledge, another form of the global flows of extraction, from design studios to remote project sites (Who Builds Your Architecture, 2017, p. 46); and maps material networks by major corporations, such as Saint-Gobain (the 2019 materials market leader with $\$ 49.3$ billion in sales; see Wang, 2019), LaFargeHolcoim, and Georgia Pacific, suppliers of curtain wall, cementitious products, and gypsum board, respectively (Who Builds Your Architecture, 2017, pp. 48-9). 
As a pull factor, migrant construction labor is a type of human extraction experienced early in the life-cycle of built environment projects. Harder to quantify are the delayed effects of this pull and of the push of human extraction that happens over time in response to hyperbuilding and other forms of construction. Scholarly studies describe the scope of more immediate displacement wrought by urban development projects. ${ }^{4}$ But gradual community displacement due to declining affordability, gentrification, or shifts in land and building use types, such changes in zoning from housing to office use or agricultural to industrial use, is slower violence, and its extractive effects can and should be similarly highlighted. A 2019 National Community Reinvestment Coalition report based on U.S. Census Bureau and other data, found that:

... many major American cities showed signs of gentrification and some racialized displacement between 2000 and 2013. Gentrification was centered on vibrant downtown business districts, and in about a quarter of the cases it was accompanied by racialized displacement. Displacement disproportionately impacted black and Hispanic residents who were pushed away before they could benefit from increased property values and opportunities in revitalized neighborhoods. This intensified the affordability crisis in the core of our largest cities.

(Richardson et al., 2019)

In circumstances favorable to community activism, local mobilization and resistance have recently emerged to counter this form of extractivism. A combination of tactics, including direct action, lobbying, and litigation, is succeeding in making visible instances where communities have experienced displacement owing to increasing unaffordability as a result of governmental changes in allowed built environment use type and/or density. In New York City in 2019 and 2020, three neighborhoods" have "thwarted or stalled both private and public efforts to develop thousands of new apartments," the majority of which, including the units offered at below-market rents, would be too expensive for longtime local residents:

With a glut of empty luxury apartments and the industry's waning influence ... momentum is building for neighborhood groups that are pushing back against new building projects because they believe such plans offer little community benefit ... Tall towers that critics say exceed height limits are being held up in litigation. Zoning loopholes that enabled skyscrapers on mid-rise blocks are being scrutinized, and could even result in the shortening of some towers. And in neighborhood rezoning battles, mostly in lower-income communities of color, opponents are fighting efforts to spur new and largely market-rate construction that they say would displace longtime residents 
Legal injunctions and temporary restraining orders have provided delays intended to provide more thorough reviews of impacts: salutary tactics, but only in the short term. The development and formalization of an assessment and citizen review process remain to be achieved.

\section{Extracting Urban Spatial Territory for Unproductive or Unneeded Use}

Leaving built environment decision-making to investors and to local and national governments eager to expand their tax base and/or prestige could result in a form of real estate waste: property vacancy. Vacancy is the result of a mismatch between development desires and human needs: between developer projections that happen in a too-narrow sphere of analysis, without considering social context or longer time frames. For example, in 2019 as employment in the neighborhood fell by 0.7 percent Washington, DC's downtown business district office vacancy rates rose to 15.5 percent, their highest level since the start of market tracking in 1993 (DowntownDC, 2020). Office vacancy rates in 2018 for global cities included in ESRI's “Top 5 Most Homeless Cities Around the World" were 15.2 percent for Los Angeles, nine percent for Moscow, 14 percent for Mumbai, and 7.7 percent for New York (ESRI ArcGIS Story Map, n.d.). Sometimes owner speculation and projections for future use keep recently built vacant properties vacant, since costs are minimal to hold onto an unoccupied asset (although some local governments are imposing punitive real estate taxes, or "vacancy taxes," on vacant space, especially street-level space; Loh and Rodriguez, 2018)). The social costs of vacancies include diminution of community life and a rise in demand and property rents that could displace people by making neighborhoods unaffordable or inaccessible. A process that results in new construction less wasteful of space, society, and site environment-a process that would demand reconceptualization of the status of the architectural and infrastructural object beyond its material form and individual site-would alleviate some of the violence which real estate waste and unaffordability exact upon communities.

\section{Soil Extraction}

Waste is inherent in the act of construction. By some estimates, construction waste accounts for 30 percent of the total weight of building materials delivered to a building site (Osmani, 2011). Materials are cut and fitted with their remnants discarded, or they are damaged in construction or over-ordered, circumstances increasingly scrutinized in search of efficiency gains to achieve a circular economy. Yet material flows studies of construction and demolition (C\&D) waste typically exclude the waste of soil excavation from construction sites, making the practice of soil excavation another form of less-visible if potent extractivism in the construction of the built environment. 
Various regional estimates suggest its extent. One study of European Union waste put the average generation of C\&D waste in 2011 in the EU at 700 million tons without excavated soil, estimating that if excavated soil was included, this value would double or even quadruple to between 1,350 to 2,900 million tons/ year (Biointelligence Service, 2011, cited in Córdoba et al., 2019). Soil excavation occurs in part because of the need for safe and stable foundations for buildings and infrastructure, where ground is extracted to a depth determined by structural engineering concerns, and it happens as a consequence of site grading (cutting and filling) undertaken to level sloping ground for human use. The question becomes, to what extent is this disruption of soil and site ecology required to service the demands of competitive hyperbuilding and the quest for the iconic architectural object sustainable? Are super-tall buildings really that necessary in locations where geological conditions do not favor their construction?

In the era of hyperbuilding, super-tall structures, defined as buildings in excess of 300 meters (about 1,000 feet) in height, have increased in global number by more than ten times in the last 25 years (Poulos, 2016), to a current total of 170 (Architect Magazine, 2019). Foundational depth allows super-tall buildings to meet their site-specific challenges, whether wind loads or site geology and soil strength or seismic factors, usually by creating an extensive below-ground support system for stability; for example, the 632-meter (2,073 feet) high Shanghai Tower required 980 foundation pilings of 86 meters (or 282 feet) depth and a foundation mat 6 meters (20 feet) in depth (Risen, 2013). The essential material of contemporary foundations is reinforced concrete, the production of which advances the consideration of another less-visible source of modern hyper-extraction: sand mining.

\section{Sand Mining and the Extractive Burden of Concrete}

Concrete is not a primary material. The most widely-used man-made material on earth, it is a mix of components (binders, aggregates, admixtures and other additions, and water) whose manufacture makes it one of the most carbon-intensive building materials, the source of about 8 percent of the world's carbon emissions (Rodgers, 2018). In addition to its use in foundations and infrastructure (currently intensifying in global hydroelectric dam construction) as prized for its solidity, concrete has become the material of choice for barrier methods (like flood walls) for climate change adaptation even as it, paradoxically, contributes to climate change through its emissions. The British-based newspaper The Guardian's 2019 "Concrete Week" reporting describes the environmental and human health impacts of concrete, and also its capacity as an instrument of political corruption and construction kickbacks (Watts, 2019). The chain of corruption and extractive impacts is particularly vivid in the mining of concrete aggregate, most commonly sand and gravel.

With the global use of materials by the construction sector estimated to more than double between 2017 and 2060, to almost 84 gigatons (GT) use, the OECD (OECD, 2019, p. 90) projects strong increases in the use of non-metallic minerals 
which represent the largest share of total materials use, projected to grow from 44 to 86 GT between 2017 and 2060, with the largest growth in tons for sand, gravel, and crushed rock (2019, p. 118):

Sand, gravel and crushed rock for construction alone represent almost 24 percent of materials extraction ... [in terms of] materials extraction across regions and development levels ... non-metallic minerals are the largest group, given that these consist of relatively low-value bulk commodities (like sand and gravel) that are expensive to import and thus normally sourced domestically.

(OECD, 2019, p. 120)

But it cannot always be sourced domestically. The world mines and uses 50 billion tons of aggregate per year (Beiser, 2019). Desert sand, with edges eroded from wind, is ineligible for use as aggregate; concrete demands angular sand granules dredged from such sources as sea floors, lake beds, floodplains, and shorelines. Dubai, for example - a city bordering the Arabian Desert-imports its sand from Australia (Beiser, 2019). A 2019 commentary in the journal Nature describes sand extraction as a landscape of "unsustainable exploitation:"

This extraction of sand and gravel has far-reaching impacts on ecology, infrastructure and the livelihoods of the 3 billion people who live along rivers ... For example, sand mining on the Pearl River (Zhujiang) in China has lowered water tables, made it harder to extract drinking water and hastened river-bed scour, damaging bridges and embankments.

Most of the trade in sand is undocumented. For example, between 2006 and 2016, less than 4 percent of the 80 million tonnes of sediment that Singapore reported having imported from Cambodia was confirmed as exported by the latter. Illegal sand mining is rife in around 70 countries, and hundreds of people have reportedly been killed in battles over sand in the past decade in countries including India and Kenya, among them local citizens, police officers and government officials ... In many countries, sand mining is unregulated and might involve local 'sand mafias.' Methods of extraction range from dredging boats and suction pumping to digging with shovels and bare hands, both in daylight and during the night.

Extraction of sand and gravel from active sources can cause great environmental, social and economic harm ... the Vietnamese government estimates that nearly 500,000 people will need to be moved away from river banks that are collapsing as a result of sand mining in the channel.

(Bendixen, 2019)

To add to its list of harms, in various geographies concrete is by weight the most wasted building material at the end of its life, since recycling is much rarer for nonmetallic minerals (although concrete waste may be used as road filler; OECD, 2019, pp. 144-145). The cumulative tally of construction minerals extraction 
impacts includes further examples of slow harm, such as the loss of biodiversity, habitat alteration, soil compaction, and the interruption of site hydrology through the sealing of land area (2019, p. 184).

\section{Green Building Development, Rating Schemes, and Extractivism}

These forms of extractive violence-harmful labor practices, displacement, vacancy, and hyper-building and -extraction-are not a particular focus of green building rating schemes. What, then, is a "green" project? If development constructed with exploitative labor practices, corrupt supply chains, and displacement of humans and other species can receive green certification, does this mean the green building movement masks these forms of violence?

Not, perhaps, intentionally. But this is an era for green building certifications, which most commonly apply at the scale of the single building or piece of infrastructure, to redefine the built environment object in other than material or resource-consuming terms, or as it prioritizes its occupants in terms of indoor environmental quality and proximity to services and recreation. We have travelled far from the early 1990s context and origins of the two pioneering new constructionorientated certifications: Leadership in Energy and Environmental Design (which in addition to the United States counts China, Singapore, the United Arab Emirates, Brazil, and India as among its primary geographies for market uptake; Gregor, n.d.) and the Building Research Establishment Environmental Assessment Method (used in 86 countries, but most intensively in Europe; see BREEAM, n.d.). Still urgently necessary are the quantitative measurements these certifications demand for the reduction of carbon and embodied carbon: after all, in the service of their credibility and market uptake, green building rating schemes have been built on what they can transparently and objectively measure. The vision which they embrace, that of voluntary "market transformation," hinges on the data-driven willingness of the leaders of our real estate economy- manufacturers, developer/investors, suppliers, building owners and tenants, and others - to adopt resource efficiency and carbon reduction measures: first, because they result in economic savings, and secondly because of all other reasons, whether regulatory or values-driven (the need to adhere to local carbon limits and/or corporate sustainability plans). Market transformation wrought by the green building movement has led to the production and acceptance (as a consumer standard) of lower-carbon, resource-efficient products and systems, and the subsequent adoption of efficiency standards by local and regional governments. Resource efficiency and governmental policy for low-carbon outcomes have bolstered economic health while contributing to a decline in carbon emissions in geographies like California, where, according to a 2019 National Resources Defense Council report, between 1975 and 2016 fossil fuel consumption relative to GDP output fell 70 percent (Komanoff et al., 2019). But even if the revenue gathered from state-imposed carbon taxes or cap-and-trade programs is redistributed to communities or ecologies judged to need them most, these benefits do little to address slow, systemic violence of the kind discussed here. 
Because (by design) they reward time-limited predicted or actual performance, green building rating schemes do not measure the longer-term consequences of the interaction of buildings and infrastructure with human communities and local and regional ecologies, and the fact that over time, building can destroy as much or more than it creates. It is time for green building rating schemes to reframe the architectural or infrastructural object as a socio-ecological force first, and a material thing second, and to widen its subject territory to include communities and ecologies well beyond its specific site, and over the span of its entire life-cycle and beyond.

\section{Reframing the Constructed Object in Space and Time}

Sociologist Saskia Sassen observes that urban areas are at risk of becoming "conflictive spaces," "overwhelmed by inequality and injustice" (Sassen, 2017). How can we incorporate an awareness of the impacts of an extractive built environment into the design process to help forestall such outcomes? How can we better understand, across time, the social and ecological complexity of the constructed object and its impacts?

We can begin by conceiving of built environment objects as forces in a web of socio-ecological relationships and querying them accordingly. Buildings and infrastructure are socio-spatial actors in social and ecological systems in a range of nested scales, from the local, to the regional, to the global. We must learn, as citizens and non-experts, to ask tough questions of existing and (especially) of proposed objects in the built environment, since these will outlive us, with impacts of correspondingly long duration. Who will benefit from this construction, and how? Who or what will occupy the constructed object? Who will manage or police it? Is it accessible to "outsiders"? Whom does it privilege and exclude, in terms of race, gender, age, or affluence? How does it relate to its place in scale and orientation? What social, racial, and economic fault lines will it exacerbate in its neighborhood and regional surroundings in the short, medium, and long terms? How will its construction alter the site and regional ecologies? How does it address current and future needs in terms of social equity and climate resilience outcomes? Who built or will build this, and how? What are the primary materials of construction, what social or power-wielding status do their choices imply, and what extractive impacts do they embody? Is the constructed object adaptable for other uses as community demographics, needs, and the very climate itself change?

A citizenry accustomed to asking these and other questions impels the need for new processes to precede, accompany, and assess the impacts of new construction over time: in other words, a longer design and review life-cycle than at present, one that parallels the life-cycle of the constructed object. This reimagined process would include the following sequential actions:

1. Transparent reporting, in the public sphere, of investor sources and amounts of capital investment in proposed commercial real estate and infrastructure projects. 
2. Prior to design, a socio-spatial assessment of neighborhood and regional conditions, demographics, and needs, to be funded and led by design and investor teams and ground-truthed by citizens.

3. As part of the design process, an investor-funded analysis of how the proposed development will increase community capacity for climate change adaptation and resilience.

4. An accounting, by the design team, of the extractive impacts of proposed materials choices.

5. A projected plan for socially-equitable project access and management over time, to note neighborhood and regional connections, and outcomes capable of violence reduction.

6. A plan, developed by project designers, for adaptive reuse of the constructed object and for eventual end-of-life demolition, as or if necessary.

7. As a precondition of construction, a time-limited citizen-led project review process, through compensated citizen service or expectations of public service akin to jury duty.

8. During construction, transparent reporting of contractor and subcontractor labor practices, including hiring and workforce training.

9. Using a small percentage of subsequent investor profit, the creation of a public escrow fund to document future development effects over time, at intervals to be determined, for incorporation as part of the public record of development effects.

The end goal is an outcomes-orientated design and monitoring process accounting for the trajectory of projects over their life spans and beyond. Through a holistic, life-cycle approach to embedding social and climate resilience considerations within the design and continuing assessment of buildings and infrastructure, this process would recognize and highlight the variety of social and climate justice impacts tangibly manifest in development schemes, and incorporate disclosure and transparency as the first steps towards action and eventual social transformation.

\section{Getting Beyond the Extractive Status Quo}

One of the aims of this reframing and its accompanying process is to shrink the distance between the actors in development-investors, designers, and community - to arrive at a common understanding of the potential for social and ecological violence from development impacts, and to forestall these. In some measure, this process seeks to parallel the fundamental goals of the environmental impact statement (EIS) required for many infrastructure projects ${ }^{6}$ as mandated in 1969 by the National Environmental Policy Act, which:

“... does not prohibit harm to the environment, but rather requires advanced identification and disclosure of harm ... An EIS outlines the status of the environment in the affected area, provides a baseline for understanding the 
potential consequences of the proposed project, identifies positive and negative effects for the environment, and offers alternative actions, including inaction, in relation to the proposed project."

(Middleton, 2018)

Conceived as a process to influence outcomes and alter the norms of decisionmaking, over time the EIS process has tended towards pro forma production by EIS expert "shops," open to underestimation of, or political influence in, its depiction of environmental outcomes (Cashmore, 2004). The alternative process of socio-spatial and climate impact assessment proposed here would differ from the EIS and typical green building certification processes in significant ways-differences in phasing, authorship, scope, methods, proof of adaptable use and climate change resilience, and an inventory of extractive concerns for material and labor choices-differences intended to reduce or avoid the violent consequences of extractivism in the built environmentspecifically:

- A required pre-design assessment. Unlike traditional environmental impact assessment, which as a screening tool occurs and is used after the selection of a preferred design, the first steps of assessment would occur before the initial design phase in order to inform and form the design path.

- At pre-design, an enlarged contextual scope of analysis. The socio-spatial assessment aims to make, as the foundation of design, context, community, and the potential for change itself. It would document historical patterns, reaching backward and then forward in time to analyze and project the social, spatial, and ecological impacts of the new construction project over a longer life-cycle than traditional impact assessments. It would account for traditions of use and social segregation in order to posit future, less violent social, ecological, and economic scenarios.

- Authorship by the design and investment team in consultation with the community, rather than by independent authorities. Traditional environmental impact assessments or statements are usually created at significant cost by independent authorities, who as third-party experts are not necessarily connected to the geographical location of the project and certainly not connected to the project design team. This new process would turn the assumed benefit of independent authority on its head, instead requiring that design and development teams embed in the proposed project location for purposes of research. The aim is to shrink the distance between local community realities and needs, and the assumptions of increasingly globally-based design firms and investors. For this reason, in order to enhance awareness and accountability the assessments at pre-design and design stages are emphatically NOT to be carried out, as are environmental impact and social impact statements, by experts, or "independent" third party authorities, but rather by the sponsors themselves.

- Different and varied assessment methods. The project team should consider interacting with the community in which it proposes to develop in a manner 
different from the usual: one in which investors and designers, with the involvement of citizens and local governments, act as historians, ethnographers, and documentarians of the context of their proposed developments. ${ }^{7}$ Rather than relying on self-selecting participation in community input meetings or charrettes - participation which often favors participation by the least vulnerable-design and investment teams should aim to meet community members where they live and work, through street-intercept surveys as well as targeted interviews with a representative cross-section of members of the affected community in a predetermined radius around the proposed project, and conducting time-noted, place-based observational studies of spatial use by humans and other species of the project's physical context. This differs from standard "best" practices in participatory design: community meetings which tend to involve those with the leisure and motivation to participate, rather than a true cross-section of community members. Project teams should consider going beyond more typical social impact assessments by using a variety of research and documentation methods: surveys, interviews, short films, observational studies of public space and ecological conditions, and oral histories, in addition to the more quantitative data-driven economic and demographic trend summaries and projections.

- Demonstrated resilience of the proposed project to climate change, and the adaptability of the design to alternative future socio-spatial uses. Projecting the adaptability of a project as part of the design process would help defer obsolescence of the constructed object, and adding to its longer life-and thus to fewer extractive new construction cycles requiring capital and materials expense.

- Making extractive impacts visible through the documentation of flagged concerns for site development, labor practices, and materials choice and intensity.

Disadvantages would ensue in thus disrupting the current status quo, although some might consider these disadvantages to be benefits. These include a lengthier design process - although less lengthy than the time added by potential lawsuits and injunctions; less profit - though perhaps more secure returns-for investors, who would fund this process, and added administrative record-keeping and longterm process management on the part of local governments, although this ongoing oversight could have the beneficial effect of improving outcomes. The possible advantages in implementing this alternative assessment process are many, including (1) awareness towards remediating the harm of persistent legacies of capitalism, globalization, and colonialism in design and materials and labor choices, through the engagement and accountability of informed citizenry and investors; (2) a resulting increase in longer-term community political capacity, and social, ecological, and economic health and conflict reduction, and thus a potential increase in longer-term profits for investors; (3) increased adaptive reuse of existing buildings as a lower-carbon alternative to new construction (the renovation of which would not be subject to this process), in which ecological and social costs are already embedded; (4) increased human and climate resilience; (5) opportunities to learn 
from the historical record of development and decision-making thus created; and (6) the more widespread establishment of the habit of mind of systems thinking, as applied to the life-cycle of development projects across local, regional, and global scales.

A timely next step rests with green building rating and certification schemes. The challenge for these is to reframe their essential definitions and inform concepts towards a new idea of what it means to be green. Defining an architectural or infrastructural object as a socio-ecological force first, and a material thing second, means that we cannot continue to ignore the impacts of construction which last far beyond their material lifespan. Enlarging a certification project's subject territory to include communities and ecologies well beyond its specific site brings awareness of, and accountability for, a wider scale of harm. And by considering the impacts of the whole project life-cycle and beyond, green building certification schemes would be better able to lead those with the power to commission such projects towards a future of less violent consequences.

\section{Notes}

1 The Climate Bonds initiative has evolved a taxonomy (Climate Bonds Taxonomy, 2020) of green investment based on comparison with a conventional baseline of energy production, water and transport infrastructure, land use, and more, which only minimally addresses extractivism, and that mostly in the waste category.

2 Designer of projects such as the CCTV Tower in Beijing, with a construction budget of over $\$ 1$ billion and a floor area of over 4,000,000 square feet.

3 There is, in addition, a rich literature on "remittance houses" as a push factor in migration and their influence on the culture of Latin American peri-urban towns (Blitzer, 2019; Janetsky and Stunt, 2020) and as chronicled in the work of Sarah Lynn Lopez on "house envy" and the remittance landscape (Lopez, 2015). There is a perverse circular effect in the construction of remittance houses in towns in the Global South: a phenomenon enabled by the Global North's employment of remittance senders as construction workers, who thereby fund a construction workforce back home and engender a locally competitive desire for the prestige which comes with large house ownership.

4 For an example, see a Brookings Institution tally (Robinson, 2003, p. 19).

5 The resisting neighborhoods have learned from the experience of two rapidly gentrifying New York City neighborhoods, Williamsburg and Greenpoint, which, as the result of zoning policies favoring market rate developments, experienced "the highest median rent increase of the decade, from $\$ 1,207$ in 2010 to $\$ 1,854$ in 2018 - a 54 percent jump, according to the NYU. Furman Center" (Chen, 2020).

6 As regards environmental impact assessments, the American Bar Association says that in addition to the USA, "over 100 countries, including Australia, China, India, Nepal, and Ukraine, have adopted similar environmental assessment protocols" (Middleton, 2018).

7 A relevant and interesting set of essays on "expanding modes of [design] practice" is to be found in the journal Log (Davidson, 2020). Byrony Roberts' introductory essay observes that traditional modes of architectural design are ill-equipped to deal with issues of social complexity, and that the tools of urban planning and analysis provide a better foundation. The volume chronicles actually existing design practices which rely on social and empathetic design practices including community collaboration, ethnographic studies, use of temporary installations, and more. 


\section{References}

Amnesty International. (2016) 'The Ugly Side of the Beautiful Game: Exploitation of Migrant Workers on a Qatar 2020 World Cup Site'. Available at: www.amnesty.org/ download/Documents/MDE2235482016ENGLISH.PDF.

Architect Magazine. (2019) 'Record Number of Supertall Buildings Completed in 2019', 13 December. Available at: www.architectmagazine.com/design/record-number-of-superta 1l-buildings-completed-in-2019_o.

Atlas Arteria. (n.d.) About Dulles Greenway. Available at: www.atlasarteria.com/portfolio/dul les-greenway.

Beiser, V. (2019) Why the world is running out of sand, BBC Future. Available at: www. bbc.com/future/article/20191108-why-the-world-is-running-out-of-sand.

Bendixen, M., Best, J., Hackney, C., and Iversen, L.L. (2019) 'Time is running out for sand', Nature, 571, pp. 29-31. Available at: www.nature.com/articles/d41586-019-02042-4.

BioIntelligence Service. (2011) 'Evolution Of (Bio-) Waste Generation/Prevention And (Bio-) Waste Prevention Indicators Final Report', in Córdoba, R.et al. (2019) 'Alternative construction and demolition (C\&D) waste characterization method proposal', Eng. Sanit. Ambient, 24 (1). Available at: www.scielo.br/scielo.php?script=sci_arttext\&pid=S1413-41522019000100199.

Blitzer, J. (2019) 'The Dream Homes of Guatemalan Migrants', The New Yorker Magazine, 5 April, 2019. Available at: www.newyorker.com/news/dispatch/the-dream-homes-of-gua temalan-migrants.

BREEAM Worldwide. (n.d.) Available at: www.breeam.com/worldwide.

Brookings Partnership for a New American Economy. (n.d.). Immigrant Workers in the U. S. Labor Workforce. Available at: www.newamericaneconomy.org/sites/all/themes/pna e/img/Immigrant_Workers_Brookings.pdf.

Cashmore, M., Gwilliam, R., Morgan, R., Cobb, D., and Bond, A. (2004) 'The Effectiveness of EIA', Impact Assessment and Project Appraisal 22 (4), pp. 295-310.

Chen, S. (2020) 'The People Vs. Big Development', The New York Times, 7 February. Available at: https://www.nytimes.com/2020/02/07/realestate/the-people-vs-big-deve lopment.html.

Clabaugh, J. (2015) 'D.C. development projects attract EB-5 Chinese investors', Washington Business Journal, 11 November. Available at: www.bizjournals.com/washington/breaking ground/2015/11/d-c-development-projects-attract-eb-5chinese.html.

Climate Bonds Taxonomy. (2020). Available at: www.climatebonds.net/files/files/CBI_Ta xonomy_Tables_January_20.pdf.

DAMfirm. (n.d.) The human cost of construction. Available at: www.damfirm.com/huma n-cost-construction/.

Davidson, C. and Roberts, B. (2020) Log 48: Expanding Modes of Practice.

Donahue, B. (2020). 'The Price of Gold', The Washington Post Magazine (Weekend edition), 6 July. Available at: www.washingtonpost.com/magazine/2020/07/06/inside-troubling-lega cy-displacing-poor-communities-olympic-games-one-villages-resistance-brazil/?arc404=true.

DowntownDC. (2020). State of Downtown 2019 Report, Downtown DC Business Improvement District, Washington, DC. Available at: www.downtowndc.org/report/sta te-of-downtown-2019.

ESRI ArcGIS Story Map. (n.d.). Top Five Homeless Cities Around the World. Available at: www.arcgis.com/apps/MapJournal/index.html?appid=e56c3fcc502442ca8f86d89809fbf287.

Fiastre, P. (2019) 'ESG: The foundation of responsible infrastructure investment', IPE Real Assets Magazine, January/February. Available at: https://realassets.ipe.com/infrastructure/ esg-the-foundation-of-responsible-infrastructure-investment/10029601. 
Fisher, M. (2013) 'Qatar is suddenly investing heavily in the U.S., bankrolling D.C.'s City Center, other projects', The Washington Post, 17 December. Available at: www.washing tonpost.com/local/qatar-is-suddenly-investing-heavily-in-the-us-bankrolling-dcs-city-cen ter-other-projects/2013/12/17/1ffaceca-5c6a-11e3-95c2-13623eb2b0e1_story.html.

Global Infrastructure Outlook 2019-2023. (2019) Globe Newswire, 17 October. Available at: www.globenewswire.com/news-release/2019/10/17/1931425/0/en/Global-InfrastructureOutlook-Report-2019-2023-South-South-East-Asia-has-the-Highest-Number-of-Infrastru cture-Projects-Valued-at-US-3-2-Trillion.html.

Green, J. (2019) 'Singapore's New Garden Airport', The Dirt. Available at: https://dirt.asla. org/2019/04/08/singapores-new-garden-airport.

Gregor, A. (n.d.) Global LEED: Two Polar Opposites Cities Take the Lead in Environmental Design, USGBC+. Available at: http://plus.usgbc.org/global-leed/.

Halsey, A. (2016) 'A crusade to defeat the legacy of highways rammed through poor neighborhoods', The Washington Post, 29 March. Available at: www.washingtonpost.com/local/tra fficandcommuting/defeating-the-legacy-of-highways-rammed-through-poor-neighborhoo ds/2016/03/28/ffcfb5ae-f2a1-11e5-a61f-e9c95c06edca_story.html.

Hickman, M. (2019) 'The World's Tallest Indoor Waterfall Will Be Located in AlreadySpectacular Airport', Treehugger. Available at: www.treehugger.com/worlds-talles t-indoor-waterfall-will-be-located-in-spectacular-airport-4868431.

Hirschmann, R. (2020) Number of Construction Workers in Singapore 2013-2019, Statista. Available at: www.statista.com/statistics/1054354/singapore-foreign-construction-workers-e mployed/.

Jacobs, H. (2018) 'Dubai's glittering, futuristic metropolis came at the cost of hundreds of thousands of workers, and recommending it as a tourist destination feels wrong', Business Insider. Available at: www.businessinsider.com/dubai-development-tourism-workers-p roblem-2018-12? $\mathrm{r}=\mathrm{US} \& \mathrm{IR}=\mathrm{T}$.

Janetsky, M. and Stunt, V. (2020) Working thousands of miles from home-to build a new one, Christian Science Monitor. Available at: www.csmonitor.com/World/Americas/ 2020/0507/Working-thousands-of-miles-from-home-to-build-a-new-one.

Jones Lang Lasalle. (2020) 'Global real estate investment hits record high in 2019', The Investor. Available at: www.theinvestor.jll/news/world/others/global-real-estate-investm ent-hits-record-high-in-2019.

KNOMAD. (n.d.). Remittances Data. Available at: www.knomad.org/data/remittances.

Komanoff, C, Cavanagh, R., and Miller, P. (2019). California Stars: Lighting the Way to a Clean Energy Future, National Resources Defense Council Report. Available at: www. nrdc.org/sites/default/files/california-stars-clean-energy-future-report.pdf.

Loh, H.D and Rodriguez, M. (2018) 'Why is that house or storefront vacant?', Greater Greater Washington. Available at: https://ggwash.org/view/68318/why-is-that-houseor-storefront-vacant.

Lopez, S. (2015) The Remittance Landscape: Spaces of Migration in Rural Mexico and Urban USA. Chicago, IL: University of Chicago Press.

Martin, C. (2016) 'Building America: The immigrant construction workforce', Urban Wire, The Urban Institute. Available at: www.urban.org/urban-wire/building-america-immigra nt-construction-workforce- 0 .

Maverick, J. (2020) 'Average Annual Returns for Long-Term Investments in Real Estate', Investopedia. Available at: www.investopedia.com/ask/answers/060415/what-average-a nnual-return-typical-long-term-investment-real-estate-sector.asp.

Middleton, T. (2018) 'What is an Environmental Impact Statement?', American Bar Association. Available at: www.americanbar.org/groups/public_education/publications/tea ching-legal-docs/teaching-legal-docs-what-is-an-environmental-impact-statement-. 
Morris, H. (2019) 'The world's tallest indoor waterfall has been unveiled at the world's best airport', The Telegraph. Available at: www.telegraph.co.uk/travel/news/jewel-singap ore-changi-opening.

OECD. (2019) Global Material Resources Outlook to 2060: Economic Drives and Environmental Consequences. Paris: OECD Publishing. Available at: https://read.oecd-ilibrary.org/envir onment/global-material-resources-outlook-to-2060_9789264307452-en.

Ong, A. (2011) 'Hyperbuilding: Spectacle, Speculation, and the Hyperspace of Sovereignty', in Worlding Cities: Asian Experiments and the Art of Being Global, pp. 205-226.

Osmani, M. (2011) 'Construction Waste' in Waste [Online].

Passel, J. and Cohn, D. (2018) Unauthorized immigrant workforce is smaller, but with more women, Pew Research Center Hispanic Trends. Available at www.pewresearch.org/hispa nic/2018/11/27/unauthorized-immigrant-workforce-is-smaller-but-with-more-women/.

Post, N. (2019) 'Singapore's Jewel Mall Project Was No Walk in the Park', Engineering NewsRecord. Available at: www.enr.com/articles/47117-singapores-jewel-mall-project-wa s-no-walk-in-the-park.

Poulos, H.G. (2016) 'Tall building foundations: Design methods and applications', Innovative Infrastructure Solutions, 1 (10). Available at: https://link.springer.com/article/10.1007/ s41062-016-0010-2.

PricewaterhouseCoopers. (2017) 'Global infrastructure investment: The role of private capital in the delivery of essential assets and services'. Available at: www.pwc.com/gx/en/ industries/assets/pwc-giia-global-infrastructure-investment-2017-web.pdf.

Richardson, J., Mitchell, B., and Franco, J. (2019) 'Shifting neighborhoods: Gentrification and cultural displacement in American cities', National Community Reinvestment Coalition, Washington, DC. Available at: https://ncrc.org/gentrification.

Risen, C. (2013) 'How to Build A 2,073-Foot Skyscraper', Popular Science. Available at: www.popsci.com/technology/article/2013-02/how-build-2073-foot-skyscraper.

Robinson, W. (2003) 'Risks and Rights: Causes, Consequence, and Challenges of Development-Induced Displacement', The Brookings Institution, Washington, DC. Available at: www.brookings.edu/wp-content/uploads/2016/06/didreport.pdf.

Rodgers, L. (2018) 'Climate change: The massive CO2 emitter you may not know about', BBC News. Available at: www.bbc.com/news/science-environment-46455844.

Sassen, S. (2017) 'Beyond Differences of Race, Religion, Class: Making Urban Subjects' in Mostafavi, M. (ed.) Ethics of the Urban: The City and the Spaces of the Political. Harvard University Graduate School of Design. Zurich: Lars Müller Publishers.

Schmitt, A. (2016) 'Anthony Foxx Wants to Repair the Damage Done By Urban Highways', StreetsblogUSA. Available at: https://usa.streetsblog.org/2016/03/30/anthonyfoxx-wants-to-repair-the-damage-done-by-urban-highways/.

Subramanian, S. (2017) 'How Singapore is creating more land for itself, The New York Times Magazine, 20 April. Available at: www.nytimes.com/2017/04/20/magazine/how-singap ore-is-creating-more-land-for-itself.html.

Wang, T. (2019) Leading manufacturers of construction materials worldwide as of April 18, 2019, based on sales, Statista. Available at: www.statista.com/statistics/314988/leadingbuildinc-material-manufacturers-worldwide.

Watts, J. (2019) 'Concrete: The most destructive material on earth', The Guardian. Available at: www.theguardian.com/cities/2019/feb/25/concrete-the-most-destructive-material-on-earth.

Who Builds Your Architecture? (2017) A Critical Field Guide. Available at: http://who builds.org/wp-content/uploads/2017/02/WBYA_Guidebook_spreads.pdf.

Who Builds Your Architecture? (n.d.) 'Projects from Doha, Chicago, New York, and Istanbul'. Available at: https://graphcommons.com/graphs/15aab298-4e75-45eb-9383-3ffd98bb67bd. 